\title{
LAS ZOONOSIS PARASITARIAS: PROBLEMA DE SALUD PÚBLICA EN EL PERÚ
}

\section{[PARASITIC ZOONOSES: A PUBLIC HEALTH PROBLEM IN PERU]}

\author{
Cesar Naquira ${ }^{1}$
}

El término zoonosis, etimológicamente, deriva de las raíces griegas zoo: animal y gnosis: enfermedad, y comprende a las enfermedades infecciosas transmisibles en condiciones naturales, entre los animales vertebrados y el hombre, donde los animales son la parte esencial en el ciclo biológico del agente etiológico, que pueden ser priones, virus, bacterias, hongos y parásitos. La FAO estima que el $60 \%$ de los patógenos humanos están relacionados con las zoonosis ${ }^{(1)}$.

Las zoonosis presentan dos aspectos a considerarse en su análisis, la infección humana y la infección animal. En algunos países tropicales y subtropicales, las zoonosis parasitarias son muy importantes por sus repercusiones en la economía y en la salud humana y animal, en especial si se trata de zoonosis en las que están involucrados animales de abasto. La importancia de las zoonosis parasitarias varía entre los países, de acuerdo con las tasas de prevalencia en seres humanos y animales, así como la posibilidad de controlarlas o erradicarlas.

En el Perú, las zoonosis parasitarias son problemas de importancia en la salud pública y en la economía (2), entre las más importantes son: la hidatidosis o equinococcosis quística ${ }^{(2)}$, la cisticercosis ${ }^{(3)}$ y la fasciolosis ${ }^{(4)}$; sin embargo, la toxocarosis está siendo objeto cada vez de mayor interés ${ }^{(5)}$.

Estas zoonosis tienen altas tasas de prevalencia en animales y seres humanos, principalmente en países de limitado desarrollo económico; los cálculos indican que las pérdidas económicas son muy altas en la producción ganadera y en la recuperación de la salud en la población humana afectada, constituyendo un determinante en el retardo en el desarrollo de dichos pueblos, con el agraviante, en el caso de la afectación del ganado de abasto, de restar proteína animal del alimento de la población ya que se tiene que desechar las vísceras y carnes infectadas, según sea la clase de zoonosis involucrada ${ }^{(1)}$.

El Comité Editorial de la Revista Peruana de Medicina Experimental y de Salud Pública (RPMESP) consideró necesario e importante que la comunidad científica del país y del extranjero, se informara de los datos actualizados y más relevantes de las zoonosis parasitarias en el Perú, con la finalidad de propiciar, por parte de los organismos públicos y privados que tienen entre sus objetivos el estudio de estas zoonosis, las medidas de control más adecuadas a nuestra realidad, utilizando el conocimiento de otros países involucrados con estos problemas y que han establecidos programas de control para atenuar o disminuir el impacto en la economía del país y en la salud humana y animal; por ello, en este número se abordan las zoonosis parasitarias de prioritaria atención en nuestro país.

Se conocen los esfuerzos de los organismos estatales y de algunas organizaciones privadas del país que realizan actividades y estudios conducentes a establecer programas de control de estas zoonosis parasitarias, por lo que consideramos que la información que los invitados al simposio dan a conocer servirá para con otros argumentos analizados por diferentes fuentes del país y el extranjero permitir la decisión de tener en un futuro no lejano, los programas de control apropiados a nuestra realidad.

\section{Hidatidosis}

La hidatidosis es la zoonosis parasitaria causada por la larva (hidátide) del cestodo Echinococcus granulosus que se ubica en el intestino del perro (hospedero definitivo), y cuyos huevos eliminados en las heces del perro contamina el alimento del ganado y otros herbívoros, incluyendo al hombre, por lo cual la larva se

\footnotetext{
Doctor en Medicina, Profesor Emérito. Facultad de Medicina, Universidad Nacional Mayor de San Marcos, Lima, Perú. Correo electrónico: cnaquira2003@hotmail.com
} 
instala, principalmente, en el hígado o pulmón del animal o del ser humano.

La hidatidosis es de relevancia en nuestro país, ya que los departamentos de la zona central andina, tienen las tasa más altas de la infección animal y humana a nivel mundial, además en estos y otros departamentos del país, la hidatidosis humana no solo es rural, sino urbana ${ }^{(2)}$.

Los datos conocidos del país sobre hidatidosis indican que la zona central andina debieran ser prioritaria para establecer un programa de control, basados entre otras informaciones en los resultados preliminares del programa piloto de control de la hidatidosis en la sierra central llevado a cabo entre 1976 - $1980^{(6)}$.

La información disponible sobre hidatidosis era fraccionada y no actualizada, en especial de los departamentos de más alta endemicidad, por lo cual, el Instituto Nacional de Salud convocó a una consultoría en el año 2008 para recabar información actualizada sobre la situación de la hidatidosis animal, humana y canina en los departamentos de nuestra serranía en áreas de alta, mediana o baja endemicidad de la sierra central y sur del Perú, uno de los estudios realizados se ha publicado en este número de la RPMESP ${ }^{(7)}$, junto con un artículo del simposio que actualiza sobre el desarrollo de las medidas prioritarias de control de la hidatidosis en los país del Cono Sur de América, que lleva decenas de años de implementación ${ }^{(8)}$.

La difusión de la hidatidosis depende de la conducta del ser humano, puesto que la infección del perro (hospedero definitivo) depende de la ingesta de la larva (hidátide) del cestodo que se encuentra en las vísceras del ganado, y el perro no ataca al ganado para tener acceso a las vísceras, es el ser humano que al sacrificar al ganado y encontrarlo con las "bolsas de agua" como define a las larvas o hidátides observados, decide no comercializarlas y las da como alimento al perro, con lo cual este desarrollará cientos a miles de gusanos en su intestino y acrecentará el peligro para el ganado y el ser humano.

Muchos de los programas de control de la hidatidosis en el mundo, se basan en elevar el nivel educativo de la población de las zonas endémicas, para evitar que el ser humano siga alimentado a los perros con vísceras crudas infectadas con la hidátide. En nuestro país, esta situación es difícil cambiar, entre otros factores, por el alto porcentaje de analfabetismo en las zonas rurales del país, donde el $19,5 \%$ de la población mayor de 15 años no tiene ningún nivel educativo, según el Censo Nacional del $2007^{(9)}$.
Los programas de control de la hidatidosis tienen como punto esencial, evitar la infección del perro y realizar la desparasitación de los canes, pues se cuenta con medicación altamente efectiva para el cestodo causante de la infección. En muchos países, son los dueños de los perros que utilizan para sus labores de cuidado del ganado, quienes supervisan el tratamiento y la vigilancia de no infección en ellos; desafortunadamente, en el Perú, la presencia de un alto número de perros vagos o una superpoblación de perros en la zonas endémicas, dificulta y encarece la realización de esta importante medida. Es necesaria la promulgación de normas que tengan como finalidad evitar la presencia de perros callejeros y el número excesivo de perros en las zonas rurales.

\section{Cisticercosis}

La cisticercosis es la zoonosis parasitaria causada por la larva (cisticerco) del cestodo Taenia solium, cuya forma adulta está presente, solamente, en el intestino del ser humano, que es el hospedero definitivo. El ser humano, portador de la tenia elimina huevos en las heces, que al ser depositadas en el suelo pueden ser ingeridas por el cerdo o accidentalmente por el ser humano. Estudios más recientes atribuyen a los malos hábitos higiénicos del portador de la tenia como el responsable de la difusión de sus huevos en el ambiente o en el alimento de personas cercanas al portador. Los huevos de la tenia, ingeridos por el cerdo o accidentalmente por el hombre, desarrollarán en ellos (cerdo y ser humano) la larva (cisticerco) estableciéndose así la cisticercosis ${ }^{(10)}$; y si la localización es el tejido nervioso, la neurocisticercosis que es su forma clínica más grave. En este número se incluye una revisión que da las pautas sobre cómo realizar el diagnóstico y el manejo clínico de la neurocisticercosis en el Perú (11).

El estudio de la cisticercosis, en nuestro país, ha estado más orientada al diagnóstico y el tratamiento, donde son muy importantes los aportes de distinguidos neurólogos y neurocirujanos en el estudio y abordaje del tratamiento de la neurocisticercosis, una menor atención se ha realizado a la epidemiología, tal vez porque los métodos de laboratorio o de estudio por imágenes en los posibles casos de nuerocisticercosis eran de alcance limitado o muy traumáticos y, además, muy limitado el tratamiento, casi siempre quirúrgico; esta situación a cambiado drásticamente en las últimas décadas con lo cual se está conociendo mejor la real situación del problema en el país ${ }^{(3)}$.

El problema teniasis/cisticercosis está siendo estudiado por el Grupo de Trabajo en Cisticercosis en Perú, cuyo centro principal es el Hospital Santo Toribio de Mogrovejo y que en los años recientes, merced al apoyo de la Fundación Bill \& Melinda Gates, ha iniciado un estudio 
integral en busca de su erradicación en Tumbes (extremo norte del Perú); en un artículo publicado en este número (3), ofrecen un adelanto importante de los resultados del estudio y los alcances en el planteamiento de un programa de control que puede llegar a la erradicación de esta zoonosis, constituyendo este aporte de suma importancia para el país y para aquellos países, como en el nuestro, donde la cisticercosis y en especial la neurocisticercosis es un importante problema de salud pública.

\section{Fasciolosis}

La fasciolosis es una zoonosis parasitaria causada por el estado adulto del platelminto trematodo Fasciola hepatica, cuyos hospederos definitivos son el ganado y animales herbívoros, incluyendo el ser humano (hospedero definitivo accidental), quienes adquieren la infección por la ingesta del estadio larvario, la metarcercaria, que en el caso del ganado, lo adquiere al ingerir las hierbas o plantas acuáticas, pasto o alimento vegetal que contienen la larva adherida a su superficie. En el caso del ser humano, es la ingesta de vegetales crudos en ensaladas preparadas, principalmente con el "berro" (Nasturtium officinale), o por la ingesta de agua que puede contener metacercarias flotantes que han sido extraídas de lugares donde existen caracoles infectados.

En el Perú, las tasas de morbilidad del ganado es muy alta en las zonas ganaderas del norte (Cajamarca) centro (valle del Mantaro) y Sur (departamentos de Cuzco, Puno, Arequipa), entre otras zonas rurales; algo similar ocurre en la población humana de dichas zonas ${ }^{(2)}$.

La repercusión en la economía regional y familiar debido a la fasciolosis animal es grave, puesto que son grandes las pérdidas en la producción de carne, leche y lanas en las comunidades afectadas; el gasto para recuperar la salud es importante, por lo que la necesidad de programas de control basados en el tratamiento del ganado y la de la población, necesitan de métodos apropiados de diagnóstico, en este aspecto es destacable el aporte del grupo de la Universidad Peruana Cayetano Heredia en el mejoramiento de los métodos de diagnóstico de laboratorio. Por ello, se incluye un artículo de este grupo, que realiza una revisión apropiada de la situación del problema, de las limitaciones para establecer un programa de control, los esfuerzos de entidades gubernamentales y privadas para un programa sostenido de control.

\section{Toxocarosis}

La toxocarosis es una zoonosis parasitaria causada por la larva del nemátodo Toxocara canis o Toxocara felis, cuyos adultos habitan el intestino de perros o gatos. Los huevos eliminados en las heces de los animales mencionados deben madurar en el medio ambiente hasta formase una larva en el interior de los mismos, en este estadio los huevos o pueden infectar a los perros y gatos contaminando su alimento o accidentalmente, el hombre puede ingerirlos al contaminarse su alimento con dichos huevos. Las larvas de estos nematodos eclosionan en el intestino del perro o gato y van a realizar un ciclo por los pulmones antes de alcanzar el intestino y desarrollarse los adultos; en el caso del ser humano estas larvas que no alcanzan nunca el estadio adulto quedan migrando en los tejidos dando lugar a la larva migrans visceral o toxocarosis ocular, principalmente, por lo que el diagnóstico requiere de pruebas serológicas de alta sensibilidad y especificidad, para los cual es necesario una metodología apropiada.

En nuestro medio, un laboratorio que viene realizado esta metodología, es el Laboratorio de Parasitología del Instituto de Medicina Tropical "Daniel A. Carrión" de la Universidad Nacional Mayor de San Marcos, que en este número publica un artículo que revisa los métodos disponibles y en desarrollo para el diagnóstico de toxocarosis ${ }^{(12)}$.

Las artículos incluidos en este número de la RPMESP, corroboran la importancia de las zoonosis parasitarias pues se exponen los puntos más relevantes en el simposio, el cual no pretende haber hecho una revisión exhaustiva de los temas, sino, darnos a conocer la importancia de estos, por su repercusión en la salud humana y de los animales afectados y en la economía de nuestro pueblo, por el alto costo que su daño y atención ocasionan; todo ello debe merecer la atención de autoridades gubernamentales así como del sector privado para proponer y desarrollar medidas apropiadas a nuestra realidad, tendientes al control y a minimizar la carga de enfermedad y mejorar la economía del país y familiar, a favor del desarrollo del país.

En la 15. ${ }^{a}$ Reunión Interamericana a Nivel Ministerial en Salud y Agricultura (RIMSA) celebrada en Río de Janeiro el 11 y 12 de junio de 2008, en la quinta conclusión del Panel 3 sobre Desarrollo Rural y Salud: dirigiendo los esfuerzos hacia la inclusión social, declara que: "Las enfermedades desatendidas y las zoonosis son una carga importante para poblaciones rurales; el fortalecimiento de su prevención, vigilancia, control y eventual erradicación/eliminación es un mandato urgente, especialmente en las comunidades rurales, con prioridad en poblaciones indígenas y otros grupos vulnerables" (13). 
Por todo lo antes mencionado, urge en el Perú implementar y fortalecer las estrategias que permitan el control de las zoonosis parasitarias.

\section{REFERENCIAS BIBLIOGRÁFICAS}

1. Steinfeld H, Gerber P, Wassenaar T, Castel V, Rosales M, de Haan C. La larga sombra del ganado. Problemas ambientales y opciones. Roma: FAO; 2009.

2. Náquira C. Las zoonosis parasitarias en el Perú, su impacto en la economía y salud del país. An Acad Nac Med (Lima). 2006;:124-26.

3. Garcia HH, Gonzalez AE, Rodriguez S, Gonzalvez G, Llanos-Zavalaga F, Tsang VC, et al. Epidemiología y control de la cisticercosis en el Perú. Rev Peru Med Exp Salud Publica. 2010;27(4):592-97.

4. Espinoza JR, Terashima A, Herrera-Velit P, Marcos LA. Fasciolosis humana y animal en el Perú: impacto en las economías de las zonas endémicas. Rev Peru Med Exp Salud Publica. 2010;27(4):604-12.

5. Huapaya $P$, Espinoza $Y$, Roldán W, Jiménez $S$. Toxocariosis humana: ¿problema de salud pública? An Fac Med (Lima). 2009;70(4):283-90.

6. Perez C. Proyecto de control de hidatidosis en el Perú por vigilancia epidemiológica. [Tesis doctoral] Lima: Facultad de Medicina, Universidad Nacional Mayor de San Marcos; 2007.
7. Santivañez SJ, Naquira C, Gavidia CM, Tello L, Hernandez E, Brunetti E, et al. Factores domiciliarios asociados con la presencia de hidatidosis humana en tres comunidades rurales de Junín, Perú. Rev Peru Med Exp Salud Publica. 2010;27(4):498-505.

8. Irabedra I, Salvatella R. EI Proyecto Subregional Cono Sur de control y vigilancia de la hidatidosis. Rev Peru Med Exp Salud Publica. 2010;27(4): 598-603.

9. Perú, Instituto Nacional de Estadística e Informática. Censos nacionales 2007: XI de población y VI de vivienda. Perfil Sociodemográfico del Perú. Lima: INEI; 2008.

10. García HH, Gilman RH, Gonzales AE, Verastegui M, Rodríguez S, Gavidia C, et al. Hyperendemic human and porcine Taenia solium infection in Perú. Am J Trop Med Hyg. 2003;68(3):268-75.

11. Saavedra H, Gonzales I, Alvarado M, Porras M, Vargas V, Cjuno A, et al. Diagnóstico y manejo de la neurocisticercosis en el Perú. Rev Peru Med Exp Salud Publica. 2010;27(4): 586-91.

12. Roldán WH, Espinoza YA, Huapaya PE, Jimenez S. Diagnóstico de la toxocariosis humana. Rev Peru Med Exp Salud Publica. 2010;27(4):613-20.

13. Organización Panamericana de la Salud. 15. ${ }^{a}$ Reunión Interamericana a Nivel Ministerial en Salud y Agricultura (RIMSA): "Agricultura y salud: alianza por la equidad y el desarrollo rural en las Américas". Washington DC: OPS; 2008.

\section{Consulte la versión electrónica de la} Revista Peruana de Medicina Experimental y Salud Pública en

\section{www.pubmed.gov}

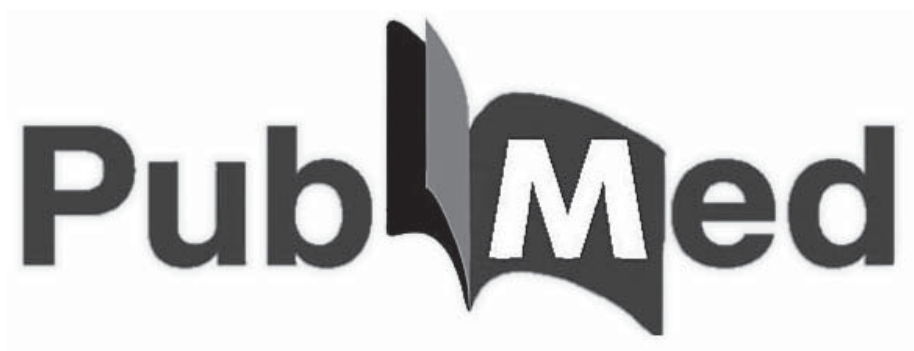

